\title{
Supporting Information: Imaging Energy Transfer in Pt-Decorated Au Nanoprisms via Electron Energy-Loss Spectroscopy
}

Sarah Griffin ${ }^{\dagger}$, Nicholas P. Montoni ${ }^{\dagger}$, Guoliang Li ${ }^{\dagger}{ }^{\text {Patrick J. Straney }}{ }^{\S}$, Jill E. Millstone ${ }^{\S}$, David J. Masiello*f, Jon P. Camden ${ }^{* \dagger}$

†Department of Chemistry and Biochemistry, University of Notre Dame, Notre Dame, IN 46556; ‡Department of Chemistry, University of Washington, Seattle, WA 98915; §

Department of Chemistry, University of Pittsburgh, Pittsburgh, PA 15260 
General materials and methods. Hexadecyltrimethylammonium bromide (CTAB, 99\%), chloroplatinic acid $\left(\mathrm{H}_{2} \mathrm{PtCl}_{6}, 8\right.$ wt. \% in $\left.\mathrm{H}_{2} \mathrm{O}\right)$ hydrogen tetrachloroaurate trihydrate $\left(\mathrm{HAuCl}{ }_{4} \cdot 3 \mathrm{H}_{2} \mathrm{O}, 99.999 \%\right)$, L-ascorbic acid $(99 \%)$, sodium borohydride $\left(\mathrm{NaBH}_{4}, 99.99 \%\right)$, sodium hydroxide (99.99\%), sodium iodide ( $\mathrm{Nal}, 99.999 \%)$, and trisodium citrate (99\%) were obtained from Sigma Aldrich and used as received. 11-amino-1-undecanethiol hydrochloride (AUT, 99.2\%) was purchased from Dojindo (Rockville, MD) and used as 
received. NANOpure ${ }^{\mathrm{TM}}$ water (Thermo Scientific, $>18.2 \mathrm{M} \Omega \cdot \mathrm{cm}$ ) was used for all washing, synthesis, and purification protocols as well as in the preparation of all solutions. All stock solutions were aqueous and prepared fresh before each reaction, unless otherwise noted. All glassware was washed with aqua regia (3:1 ratio of concentrated $\mathrm{HCl}$ and $\mathrm{HNO}_{3}$ by volume) and rinsed thoroughly with water. Caution: Aqua regia is highly toxic and corrosive and requires personal protective equipment. 
Aqua regia should be handled in a fume hood only.

Au Nanoprism Synthesis. Au nanoprisms were synthesized according to previous protocols. ${ }^{1,2}$ Two hours after Au nanoparticle seeds were added to the nanoprism growth solution, the reaction mixture was heated in a $\mathrm{H}_{2} \mathrm{O}$ bath to $37^{\circ} \mathrm{C}$ for 1 minute to dissolve any CTAB that may have recrystallized during the growth period (this

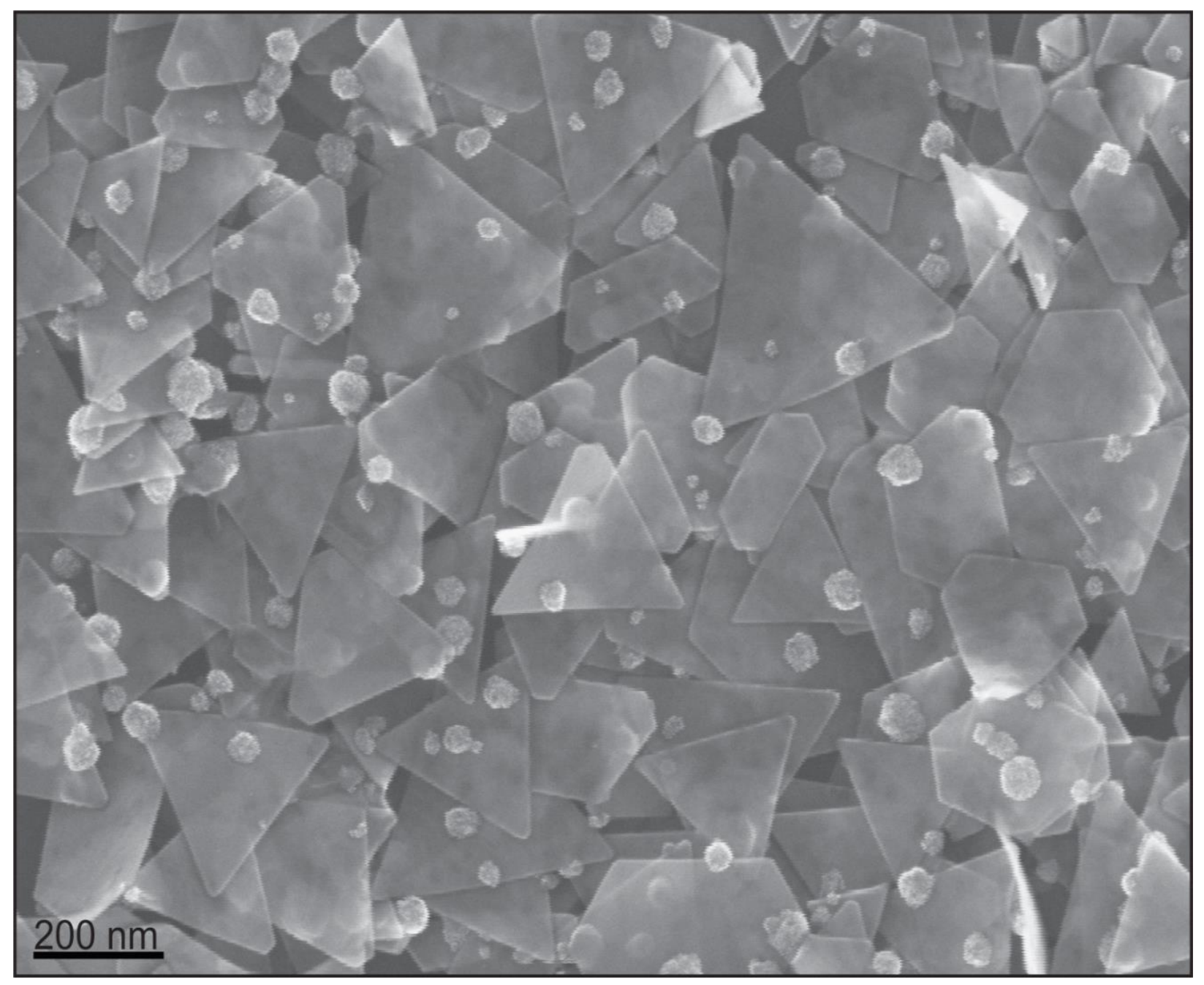

Figure 1. SEM image of the Pt-decorated Au nanoprisms. Generally, 1-3 Pt nanoparticles were observed on each Au nanoprism. Pt deposits were found to be 30 $\pm 5 \mathrm{~nm}$ in diameter. 
crystallized CTAB can interfere with nanoprism purification by centrifugation). To separate the nanoprisms from pseudospherical nanoparticle reaction byproducts, $90 \mathrm{~mL}$ of the reaction mixture was divided into $15 \mathrm{~mL}$ conical tubes and centrifuged at $820 \mathrm{rcf}$ for 15 minutes

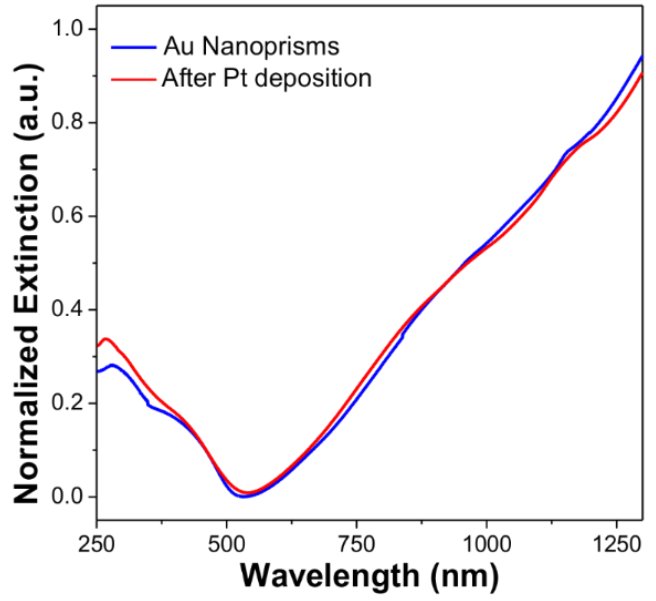
(Eppendorf centrifuge 5804 with swing bucket rotor A-4-44). The supernatant and pellet were both extracted and the nanoprism thin film was resuspended in $1.0 \mathrm{~mL}$ of $\mathrm{H}_{2} \mathrm{O}$ by vortexing for 5 seconds.

Figure 2. UV-Vis-NIR spectra of the Au nanoprisms before (A) and after (B) $\mathrm{Pt}$ depositon. No significant damping in plasmon intensity was observed. A slight red-shift (approximately $15 \mathrm{~nm}$ ) of the inplane dipole localized surface plasmon resonance (LSPR, $\lambda_{\max } \approx 1300 \mathrm{~nm}$ ) was observed after Pt deposition.

To remove additional $C T A B$ and excess reagents, this mixture was transferred to 1.5 $\mathrm{mL}$ centrifuge tubes, and the prisms were then centrifuged using a Spectrum minicentrifuge (SC1006-R) for approximately 5 minutes. After centrifugation, the supernatant was removed and the prisms were resuspended in $1.0 \mathrm{~mL}$ of $\mathrm{H}_{2} \mathrm{O}$ and subsequently combined in a $15 \mathrm{~mL}$ conical tube. The concentration of the purified nanoprisms in the nanoprism stock solution was then adjusted to an optical density (O.D.) of 1.0 a.u. at the maximum absorption wavelength ( $\lambda_{\max }$, approximately $\left.1300 \mathrm{~nm}\right)$ by ultraviolet-visible-near infrared (UV-vis-NIR) spectroscopy.

Pt-decorated Au Nanoprism Synthesis. To $1.0 \mathrm{~mL}$ of purified Au nanoprisms (absorbance at $\lambda_{\max }=1.0$ a.u.) was added $8.0 \mu \mathrm{L}$ of $1 \mathrm{mM}$ AUT. The mixture was vortexed, and the nanoprisms were allowed to rest for 24 hours to allow for thiol 
conjugation to the nanoparticle surface. After this period, $20 \mu \mathrm{L}$ of $20 \mathrm{mM}$ ascorbic acid was added, and the nanoparticle solution was vortexed briefly. Next, $20 \mu \mathrm{L}$ of $2 \mathrm{mM}$ $\mathrm{H}_{2} \mathrm{PtCl}_{6}$ was added, the solution was briefly vortexed, and the nanoprisms were allowed to rest for an additional 24 hours to ensure complete reduction of $\mathrm{H}_{2} \mathrm{PtCl}_{6}$.

UV-vis-NIR Spectroscopy. Nanoprism solutions were analyzed by UV-vis-NIR spectroscopy using a Cary 5000 spectrophotometer (Agilent, Inc.). Baselines were collected using $\mathrm{H}_{2} \mathrm{O}$ as reference solutions.

Transmission Electron Microscopy (TEM). Nanoparticle products were purified by centrifugation using a Spectrum mini-centrifuge (SC1006-R). After removal of the supernatant, the pellet was resuspended in $1.0 \mathrm{~mL}$ of $\mathrm{H}_{2} \mathrm{O}$ and the process was repeated. After subsequent removal of the supernatant, nanoprism products were resuspended in $30 \mu \mathrm{L}$ of $\mathrm{H}_{2} \mathrm{O}$ by vortexing and sonicating for approximately 10 seconds. For general TEM imaging, a $5 \mu \mathrm{L}$ aliquot of each concentrated nanoprism sample was dropcast onto a TEM grid (Ted Pella, Carbon Type A on 300 mesh Cu), allowed to dry under ambient conditions, and stored under vacuum prior to analysis. TEM images were obtained using a JEOL JEM 2100F equipped with a Gatan Imaging Filter (GIF) Tridiem camera and Oxford Inca EDS detector at $200 \mathrm{kV}$ (Nanoscale Fabrication and Characterization Facility, Petersen Institute of Nanoscience and Engineering, University of Pittsburgh), or a Hitachi Environmental TEM at $300 \mathrm{kV}$ (Department of Mechanical Engineering and Materials Science characterization facility, University of Pittsburgh). Images were analyzed using Digital Micrograph v2.10.1282.0 (Gatan, Inc.) and/or Image J v $1.47 \mathrm{~d}$ (National Institutes of Health, USA) software. 
Scanning Electron Microscopy (SEM). Silicon wafer substrates (University Wafer, ptype, $200 \mathrm{~nm}$ thermal oxide (silicon dioxide)) were first cleaned by sonicating in ethanol for $5 \mathrm{~min}$. The substrate was then successively rinsed with ethanol and acetone and dried under a stream of $\mathrm{N}_{2}(\mathrm{~g})$. Samples were prepared using the same procedure described for TEM analysis. Here, $10 \mu \mathrm{L}$ of the resulting solution was drop-cast onto the wafer and allowed to dry before imaging on a Raith Dual Beam EBL-SEM at various

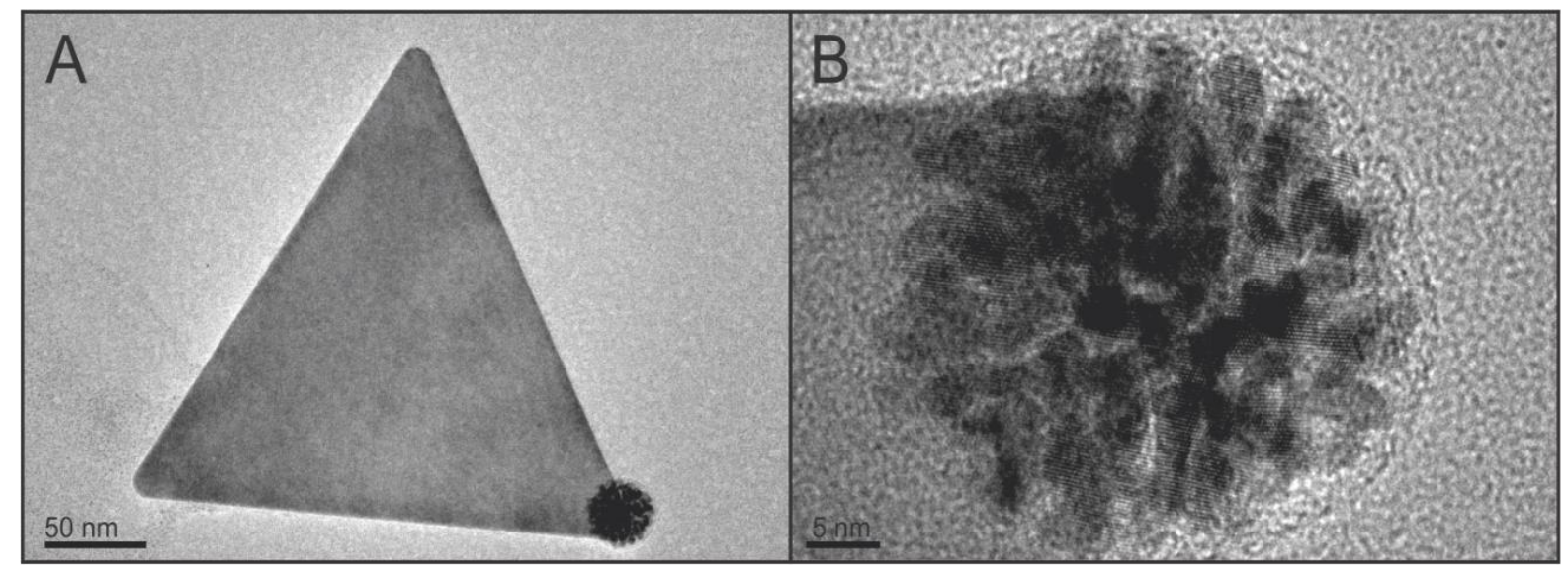

Figure 3. High resolution TEM image (HRTEM) of the Pt-decorated Au nanoprisms. (A) Image of a single Pt-decorated Au nanoprism. (B) Magnified view of a Pt nanoparticle pendant on a prism vertex, depicting the dendritic morphology of the $\mathrm{Pt}$ nanoparticle.

accelerating voltages.

1. Millstone, J. E.; Wei, W.; Jones, M. R.; Yoo, H.; Mirkin, C. A., lodide lons Control Seed-Mediated Growth of Anisotropic Gold Nanoparticles. Nano Lett. 2008, 8, 25262529.

2. Straney, P. J.; Marbella, L. E.; Andolina, C. M.; Nuhfer, N. T.; Millstone, J. E., Decoupling Mechanisms of Platinum Deposition on Colloidal Gold Nanoparticle Substrates. J. Am. Chem. Soc. 2014, 136, 7873-7876. 